\title{
Vertical to Horizontal Spectral Ratio (VHSR) Response of Seismic Wave Propagation in a Homogeneous Elastic - Poroelastic Medium Using The Spectral Finite Element Method
}

\author{
Sudarmaji ${ }^{1}$, Budi Eka Nurcahya ${ }^{2}$ and Nivan Ramadhan Sugiantoro ${ }^{3}$ \\ Department of Physics, Faculty of Mathematics and Natural Sciences, Gadjah Mada University, \\ Yogyakarta, Indonesia \\ Email: ${ }^{1}$ ajisaroji@ugm.ac.id, ${ }^{2}$ budiekanurcahya@yahoo.com, ${ }^{3}$ nivan.ramadhan.s@mail.ugm.ac.id
}

\section{ABSTRACT}

Numerical modeling of 2D seismic wave propagation using spectral finite element method to estimate the response of seismic waves passing through the poroelastic medium from a hydrocarbon reservoir has been carried out. A hybrid simple model of the elastic - poroelastic - elastic with a mesoscopic scale element size of about $50 \mathrm{~cm}$ was created. Seismic waves which was in the form of the ricker function are generated on the first elastic medium, propagated into the poroelastic medium and then transmitted to the second elastic medium. Pororoelastic medium is bearing hydrocarbon fluid in the form of gas, oil or water. Vertical and horizontal component of velocity seismograms are recorded on all mediums. Seismograms which are recorded in the poroelastic and second elastic medium show the existence of slow P compressional waves following fast $\mathrm{P}$ compressional waves that do not appear on the seismogram of the first elastic medium. The slow $\mathrm{P}$ wave is generated when the fast $\mathrm{P}$ wave enters the interface of the elastic - poroelastic boundary, propagated in the poroelastic medium and is transmited to the second elastic medium. The curves of Vertical to horizontal spectrum ratio (VHSR) which are observed from seismograms recorded in the poroelastic and the second elastic medium show that the peak of VHSR values at low frequency correlated with the fluid of poroelastic reservoir. The highest VHSR value at the low frequency which is recorded on the seismogram is above the $2.5 \mathrm{~Hz}$ frequency for reservoirs containing gas and oil in the second elastic medium, while for the medium containing water is the highest VHSR value is below the $2.5 \mathrm{~Hz}$ frequency.

Keyword: wave propagation, elastic, poroelastic, fast $\mathrm{P}$ wave, slow $\mathrm{P}$ wave, spectral finite element, VHSR, hydrocarbon

\section{INTRODUCTION}

The seismic wave propagation in fluid saturated poroelastic media based on Biot's theory is the basis for the numerical simulation of wave propagation in fluid saturated poroelastic media $[1,2]$. The finite-difference (FD) method for Biot's equations has been formulated, i.e. finite difference method in displacement ${ }^{[3]}$ and finite difference method in velocity-stress ${ }^{[4]}$. An unsplit convolutional perfectly matched layer (CPML) is the stable new an absorbing boundary condition has been implemented in finite difference method ${ }^{[5]}$. Numerical modeling of 2D seismic wave propagation in fluid saturated porous media based on finite difference method using Graphics Processing Unit (GPU) has been implemented to simple hydrocarbon (oil or gas) reservoir model ${ }^{[6]}$. Numerical modeling of 2D seismic wave propagation in fluid saturated porous media based on spectral finite element (SEM) has been implemented too ${ }^{[7-9]}$. Numerical modeling of 2D seismic wave propagation in poroelastic medium in realistic hydrocarbon reservoir trapping model has been implemented by mean spectral finite element (SEM) method too ${ }^{[10]}$.

In recent years, application of passive seismic method for hydrocarbon prospecting and exploration has received more attention ${ }^{[11-15]}$. The measurement and processing results of 
passive seismic 3C data of various oil and gas fields from various parts of the world, empirically show the existence of correlation between the peak values of the vertical to horizontal spectral ratio (VHSR) in the low frequency band with the presence of the oil or gas reservoir beneath the seismometer location. The peak value of VHSR around $2-6 \mathrm{~Hz}$ correlates with the presence of oil or gas with various fluid characters and physics properties of reservoir. While the peak value of VHSR in the frequency band least than $2 \mathrm{~Hz}$ correlates with water existence ${ }^{[11-14]}$. Not many theoretical explanations or numerical modeling that explains the existence of this empirical phenomenon ${ }^{[11]}$. Numerical modeling for the propagation of seismic waves in pure elastic medium or in pure poroelastic medium cannot explain this phenomenon.

In this study, a hybrid elastic-poroelastic-elastic medium model is proposed to show the conversion behavior of the $\mathrm{P}$ wave when it enters a different medium, from elastic medium to poroelastic medium. It will be shown that the phenomenon of high VHSR values in the low frequency band is related to the conversion of a seismic $\mathrm{P}$ wave become fast $\mathrm{P}$ wave and slow $\mathrm{P}$ wave when entering from a pure elastic medium to a fluid-saturated poroelastic medium. The conversion of seismic $\mathrm{P}$ wave and diffusive character of the slow $\mathrm{P}$ wave on the mesoscopic scale are expected to be able to change the frequency content of the seismic signal ${ }^{[16]}$. The $2 \mathrm{D}$ of numerical wave modeling is done using the spectral finite element (SEM) method on 80 cores MPI cluster, so that it can address the homogeneous hybrid elastic - porous elastic medium model with each element size around $50 \mathrm{~cm}{ }^{[8]}$.

\section{METHODS}

We use the SPECFEM2D software package [6] and decompose the model into 12104 hexahedral elements. In each spectral element we use the polynomial degree of $N=4$, and thus each element contains $(N+1)^{3}=125$ Gauss-Lobatto-Legendre (GLL) integration points. Total number of GLL points in the model is $14,124,456$. The minimum and maximum distance between Gauss-Lobatto-Legendre integration points in the model is 2-17 m respectively. We use a ricker wavelet as source time function with dominant frequency is $20 \mathrm{~Hz}$. The time step used is $\Delta t=5 \times 10^{-6} \mathrm{~ms}$ and we propagate the signal for 300.000 time steps, thus total simulation time is $1.5 \mathrm{~s}$.

Table 1. Physical properties of rock for the réservoir model

\begin{tabular}{|c|c|c|c|c|c|}
\hline \multirow{2}{*}{$\begin{array}{l}\text { Physical } \\
\text { Properties }\end{array}$} & \multirow{2}{*}{ Elastic 1} & \multirow{2}{*}{ Elastic 2} & \multicolumn{3}{|c|}{ Poroelastic } \\
\hline & & & Gas & Oil & Water \\
\hline$V_{p} \quad(\mathrm{~m} / \mathrm{s})$ & 2700 & 2750 & 2540 & 2580 & 2620 \\
\hline$V_{s} \quad(\mathrm{~m} / \mathrm{s})$ & 1185 & 1200 & 1620 & 1433 & 1247 \\
\hline$\rho_{s} \quad\left(\mathrm{~kg} / \mathrm{m}^{3}\right)$ & 2450 & 2500 & 2300 & 2300 & 2300 \\
\hline$K_{f} \quad(\mathrm{GPa})$ & - & - & 0.02 & 0.7 & 2.4 \\
\hline$\eta \quad$ (Pa.s) & - & - & 0.00001 & 0.03 & 0.003 \\
\hline$\kappa(\mathrm{mD})$ & - & - & 100 & 100 & 100 \\
\hline a & - & - & 2.0 & 2.0 & 2.0 \\
\hline$\phi \quad(\%)$ & - & - & 10 & 10 & 10 \\
\hline$\rho_{f} \quad\left(\mathrm{~kg} / \mathrm{m}^{3}\right)$ & - & - & 150 & 750 & 1000 \\
\hline
\end{tabular}

The schematic of simple hybrid model for numerical simulation is shown in Figure 1. The dimension of the model is $500 \mathrm{~m}$ x $450 \mathrm{~m}$ which contains three mediums, i.e.: elastic 1, Poroelastic and elastic 2 medium. Table 1 shows Physical properties of rock for numerical simulation. The mesh model has 900.000 elements using interpolation for domains decomposition in the form of 4th order polynomials. Spectral element sizes around $50 \mathrm{~cm}$. 
Simulation is done by placing the source point at elastic 1 medium and deploying 1 receiver in elastic 1 medium, 1 receiver in poroelastic medium and 3 receivers in elastic 2 medium. Physical properties and fluid filling the reservoir are shown in Table 1.
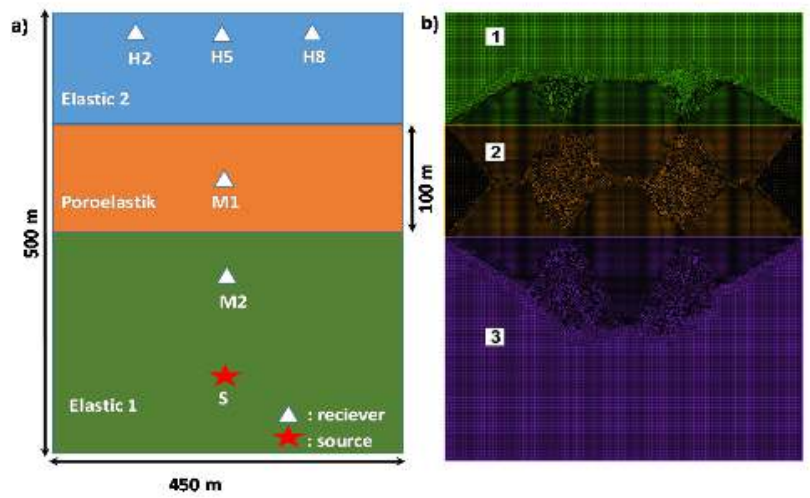

Figure 1. a) Schematic of hybrid simple model. b) Mesh Implementation model.

The numerical simulation is carried out on a computer cluster containing 7 workstations and one server with 80 core processors Intel Xeon CPU E5-620@2.4 GHz using MPI (Message Passing Interface) under the rock cluster linux operating system at Computational and Seismic Laboratory, Geophysics Sub-Department, Gadjah Mada University.

\section{RESULTS AND DISCUSSION}

\section{Seismic wave propagation}

The numerical simulation of seismic wave propagation with spectral finite element (SEM) method on elastic-pororoelastic hybrid medium using the box mesh model in Figure 1 and reservoir physics and fluid properties in Table 1. has been completed in computational time of 3 hours 38 minutes to produce propagation waves for $1.5 \mathrm{~s}$. The source of the rickerfunction (second derivative of the gaussian function) is generated at the location of source $\mathrm{S}$ in the elastic zone 1, spreads into the poroelastic zone of the reservoir and then transmitted to the elastic 2 medium. The M2, M1, H2, H5 and $\mathrm{H} 8$ recievers record the velocity of wave propagation both vertical or horizontal direction. The physical property of the poroelastic reservoir medium is set up according to the variation of the measured reservoir response. Pororoelastic reservoirs have variation of physical properties such as porosity and reservoir fluid. Reservoir fluid is in the form of Gas, Oil and Water. Wave propagation images from $\mathrm{t}=0.1 \mathrm{~s}$ to $\mathrm{t}=0.6 \mathrm{~s}$ are shown in Figure 2.

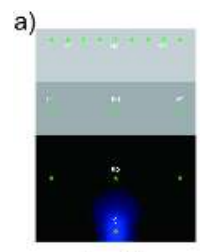

$t=0.1$

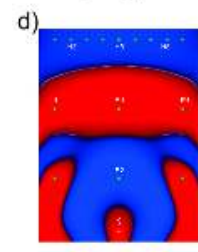

$\mathrm{t}=0.4$

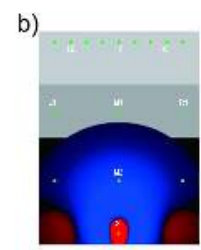

$t=0.2$

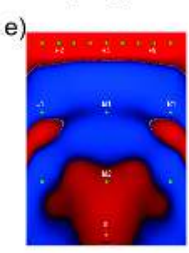

$\mathrm{t}=0.5$

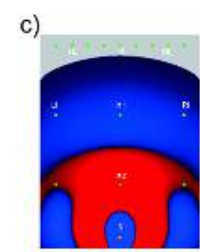

$t=0.3$

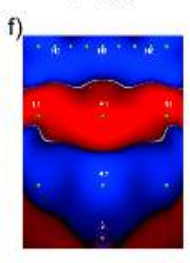

$t=0.6$

Figure 2. Wave propagation images from $t=0.1 \mathrm{~s}$ to $\mathrm{t}=0.6 \mathrm{~s}$ 
Seismograms of vertical and horizontal components of the gas, oil and water reservoir with porosity of $10 \%$ are recorded in the $\mathrm{H} 5, \mathrm{H} 2, \mathrm{M} 1$ and $\mathrm{M} 2$ receivers are shown in Figure 3. The vertical component seismograms of M1 reciever shows the presence of slow $\mathrm{P}$ wave that follow the fast $\mathrm{P}$ waves that are not recorded on the seismogram of the $\mathrm{M} 2$ reciever in the elastic zone 2. The $\mathrm{M} 2$ receiver only record fast $\mathrm{P}$ waves and their reflections. The slow $\mathrm{P}$ wave from poroelastic medium is transmitted to the elastic zone 2 following the fast $\mathrm{P}$ wave so that it is recorded in the $\mathrm{H} 5$ and $\mathrm{H} 2$ receivers too.

The horizontal component seismograms of M2, M1 and H5 reciever have a very small amplitude value range compared to their vertical component seismogram because it is in vertical line with source $\mathrm{S}$. The horizontal component seismogram of $\mathrm{H} 2$ reciever has a relatively large amplitude value because it is not vertically in line with source $\mathrm{S}$ so that it raises shear waves component. Seismic waves that pass through the reservoir medium containing gas come at the latest. While seismic waves that pass through the oil medium will come the fastest.

a)

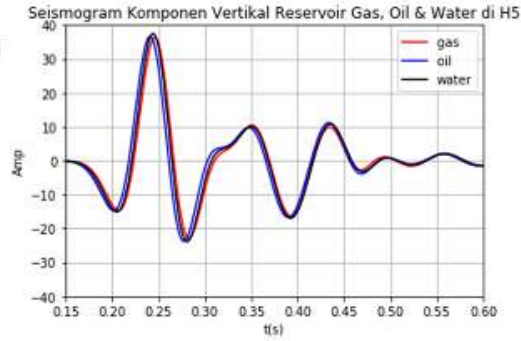

c)

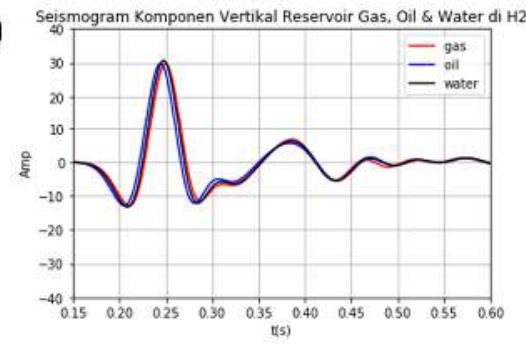

e)

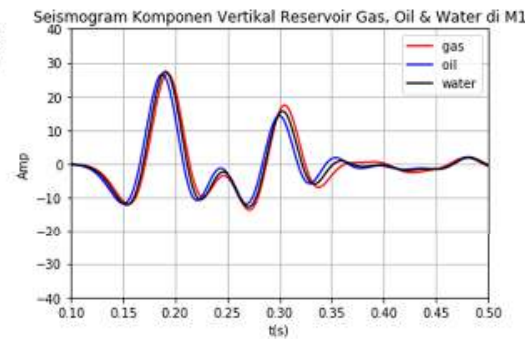

g)

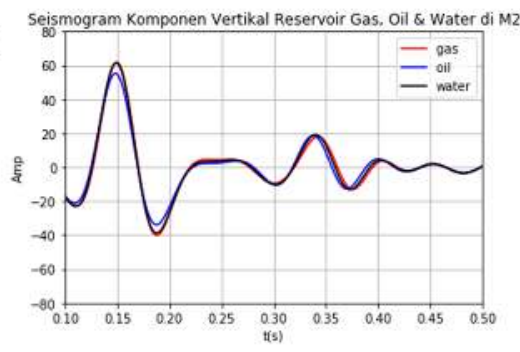

b)

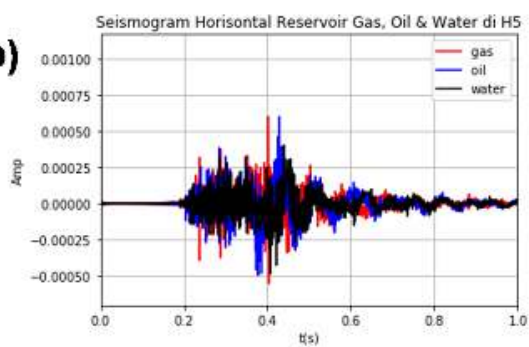

d)
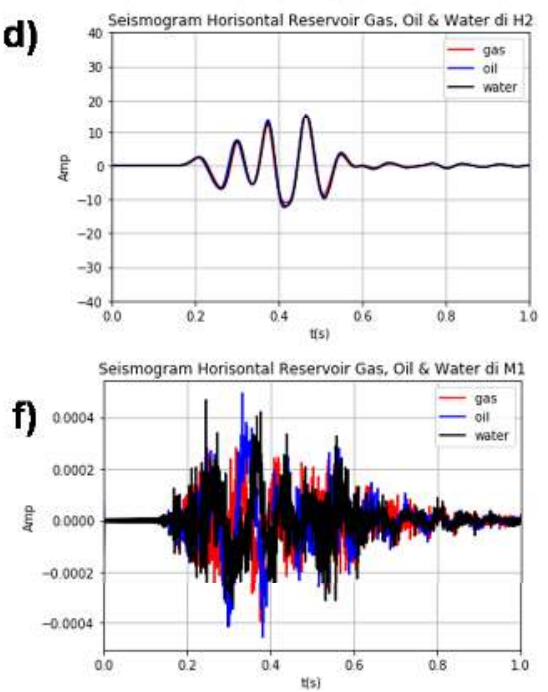

h)

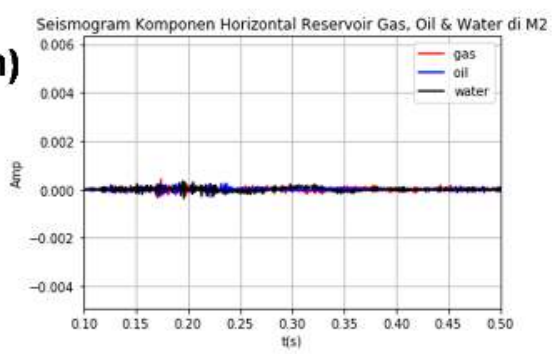

Figure 3. Vertical and horizontal components seismograms with porosity $10 \%$ of gas, oil and water reservoirs. a) vertical component seismogram of $\mathrm{H} 5$ reciever, b) horizontal component seismogram of $\mathrm{H} 5$ reciever, c) vertical component seismogram of $\mathrm{H} 2$ reciever, d) $\mathrm{H} 2$ reciever horizontal component seismogram, e) Vertical component Seismogram of M1 reciever, f) Horizontal component seismogram M1 reciever, g) vertical component seismogram of M2 reciever, h) horizontal component seismogram of M2 reciever. 
The vertical components seismograms from reservoirs containing gas, oil and water with varying porosity on the $\mathrm{H} 5$ receiver are shown in Figure 4. The $\mathrm{H} 5$ receiver is located in the elastic medium 2 that receives wave transmission from the pororoelastic reservoir medium and has a vertically straight-line position with Souce S. The horizontal component wave is very small amplitude compared to the vertical component. The slow $\mathrm{P}$ wave is seen following the fast $P$ wave. Seismic waves that pass through a gas-filled reservoir with porosity of $10 \%$ arrive at the latest but have the greatest amplitude or the smallest attenuation. Seismic waves that pass through a gas-filled reservoir with a porosity of $40 \%$ arrive the fastest but have the smallest amplitude or the greatest attenuation. Seismic waves that pass through reservoirs containing oil and water have almost the same amplitude and arrival times for all reservoir porosity variations.
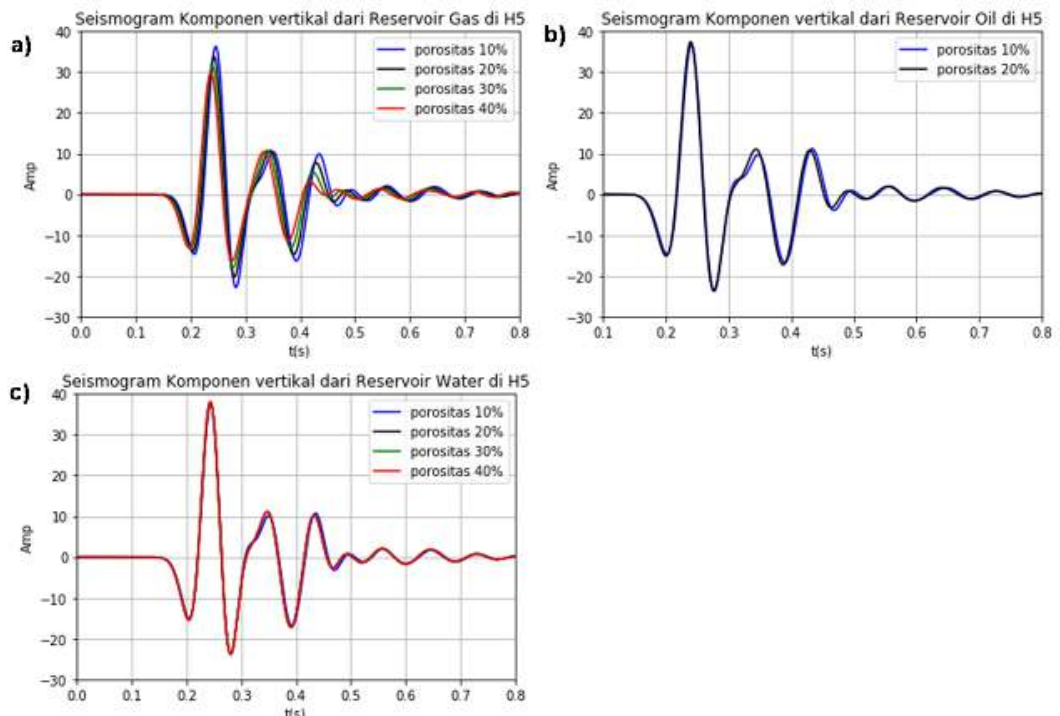

Figure 4. The vertical component seismogram of gas, oil and water reservoir with varying porosity on the H5 receiver. a) Vertical component seismogram of gas reservoir, b) Vertical component seismogram of oil reservoir, c) Vertical component seismogram of water reservoir

The vertical components seismograms of reservoirs which are containing gas, oil and water with varying porosity on the M1 receiver are shown in Figure 5. The M1 receiver is located in the poroelastic zone which receives wave transmissions from elastic zone 1 and has a vertically straight-line position with source $\mathrm{S}$. The horizontal component wave is very small amplitude compared to their vertical component. The slow $\mathrm{P}$ wave is seen following the fast $\mathrm{P}$ wave. Seismic waves in gas-filled reservoirs with porosity of $10 \%$ arrive at the latest but have the greatest amplitude or the smallest attenuation. Seismic waves in gas-filled reservoirs with porosity of $40 \%$ arrive the fastest but have the smallest amplitude or greatest attenuation. Seismic waves in reservoirs containing oil with $20 \%$ porosity have aslow $\mathrm{P}$ wave that comes faster and amplitude is greater than $10 \%$ porosity. Seismic waves from reservoirs containing water have almost the same amplitude and arrival times for all variations of reservoir porosity.

The vertical components seismograms of reservoirs containing gas, oil and water with varying porosity in $\mathrm{H} 2$ reciever are shown in Figure $6 . \mathrm{H} 2$ recievers are located in the elastic medium 2 that accepts wave transmissions from the poroelastic reservoir medium and have a position not in a vertically straight line with Souce S. Horizontal wave component has a relatively large amplitude due to shear compression of propagation wave. Slow P waves are seen to follow fast $\mathrm{P}$ waves with imperfect shapes. Seismic waves that pass through a gas-filled reservoir with porosity of $10 \%$ arrive at the latest but have the greatest amplitude or the smallest attenuation. Seismic waves that pass through a gas-filled reservoir with a porosity of $40 \%$ arrive the fastest but have the smallest amplitude or the greatest attenuation. Seismic waves that pass through 
reservoirs containing oil and water have almost the same amplitude and arrival times for all variations of reservoir porosity.
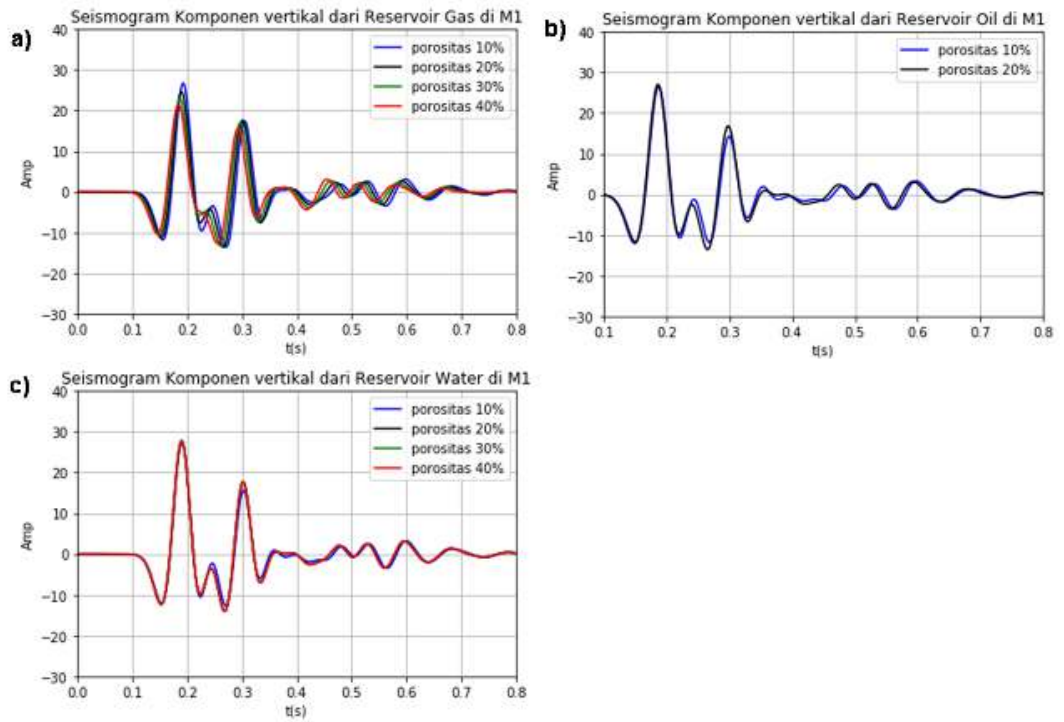

Figure 5. The vertical component seismogram of gas, oil and water reservoir with varying porosity on the M1 receiver. a) vertical component seismogram of gas reservoir, b) vertical component seismogram of oil reservoir, c) vertical component seismogram of water reservoir
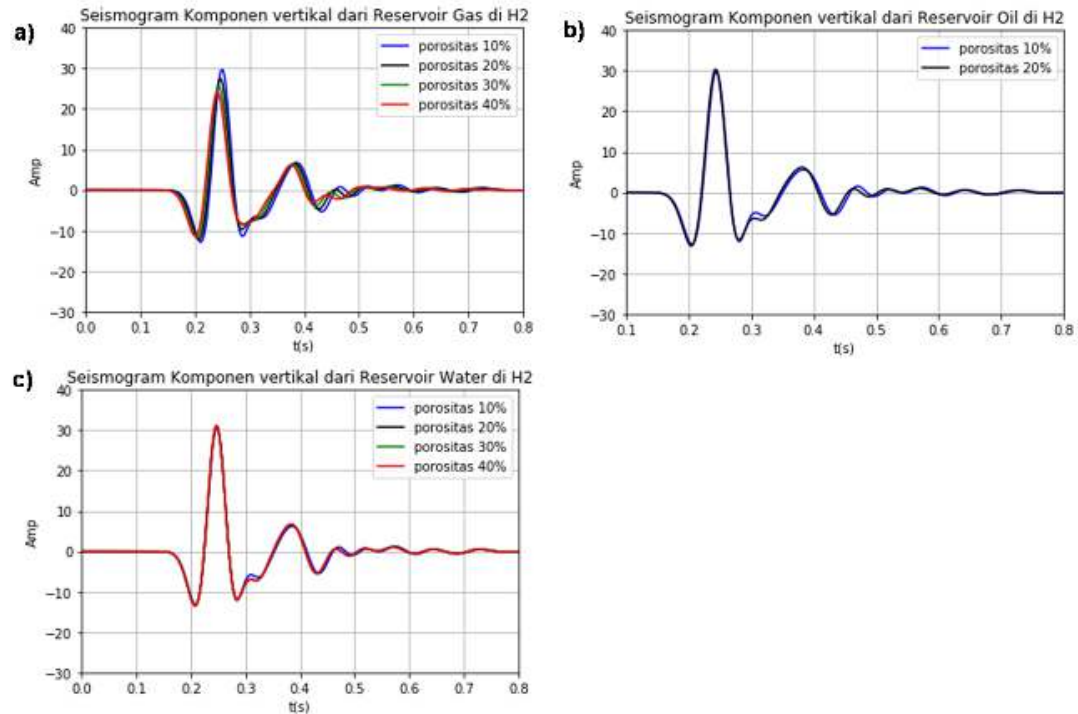

Figure 6. The vertical component seismogram of gas, oil and water reservoir with varying porosity on the M2 receiver. a) vertical component seismogram of gas reservoir, b) vertical component seismogram of oil reservoir, c) vertical component seismogram of water reservoir

\section{Vertical to horizontal spectral ratio (VHSR)}

Receiver on M2, M1, H2, H5 and $\mathrm{H} 8$ records seismogram of the wave propagation velocity in both vertical and horizontal directions, then spectral analysis is done in the frequency domain. The seismogram data from the time domain is transformed the frequency domain by mean Fourier transforms to get the spectrum. The value of the vertical component spectrum is divided 
by the horizontal component spectrum to get the vertical to horizontal spectrum ratio (VHSR). Observation of the frequency band and peak spectrum in the low frequency range is carried out.

The VHSR curve on the H5 receiver is shown in Figure 7. The H5 receiver is located in the elastic medium that receives wave transmissions from the poroelastic reservoir medium and has a vertically straight-line position with the source S. The VHSR value of seismic wave that passing through gas and oil filled reservoir has a peak VHSR curve above $2.5 \mathrm{hz}$, while a reservoir containing water has a peak VHSR smaller than $2.5 \mathrm{hz}$ at low frequency. VHSR values of seismic waves that pass through reservoirs containing gas with low porosity tend to have a higher spectrum than high porosity.
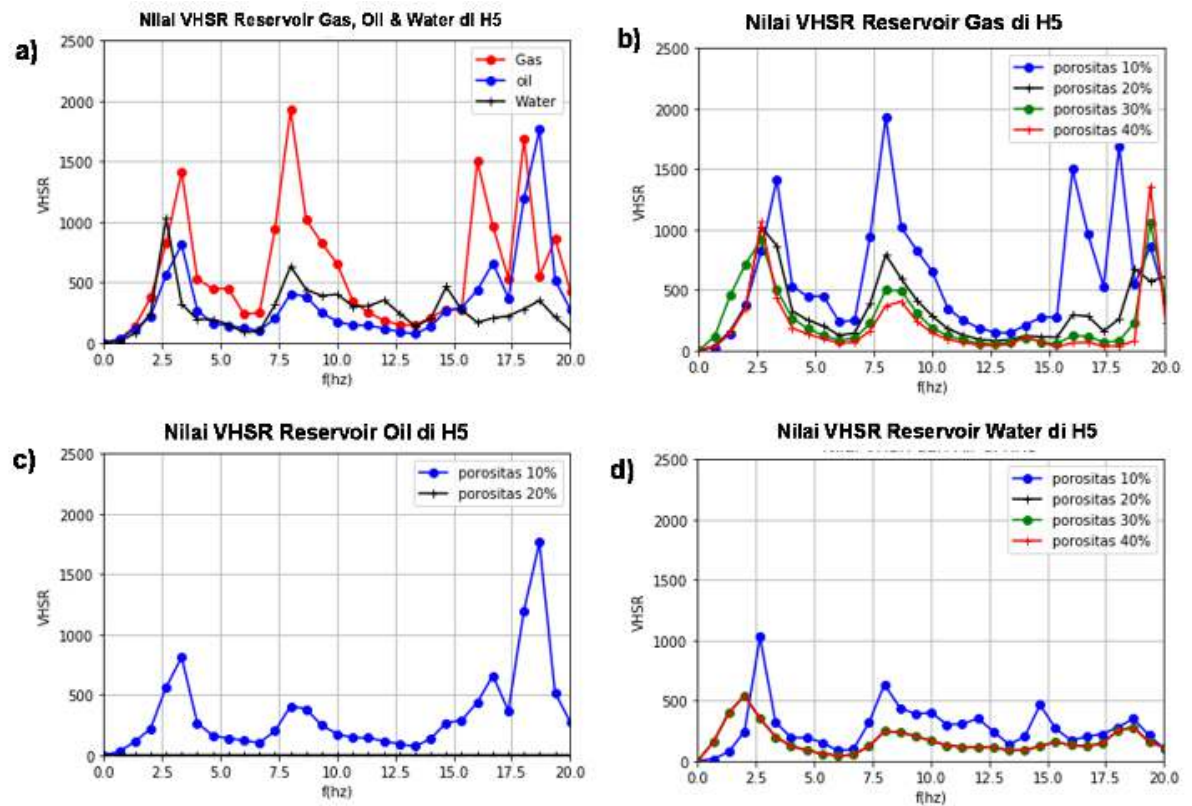

Figure 7. VHSR curve on H5 receiver. a) VHSR curves of gas, oil and water reservoir, b) VHSR curves of gas reservoir with porosity variations, c) VHSR curves of oil reservoir with porosity variations and d) VHSR curves of water reservoir with porosity variations

The VHSR curve on the M1 receiver is shown in Figure 8. The M1 receiver is located in the poroelastic medium that receives wave transmissions from elastic 1 medium and has a vertically straight line position with Souce $S$. The VHSR value of seismic waves in reservoirs containing gas, oil and water has a peak below $2.5 \mathrm{hz}$ spectrum at low frequency. VHSR values of seismic waves from low-porosity gas reservoirs tend to have a higher spectrum than high porosity.

The VHSR curve on the $\mathrm{H} 2$ receiver is shown in Figure 9. The $\mathrm{H} 2$ receiver is located in the elastic 2 medium that receives wave transmissions from the pororoelastic reservoir medium and has a position not in a vertically straight line with Souce S. The VHSR value of seismic waves passing through reservoirs containing gas, oil and water has peak spectrum well below $2.5 \mathrm{hz}$ and low value at low frequencies. The energy of the vertical component of the seismic wave is partitioned in the direction of the shear component. 

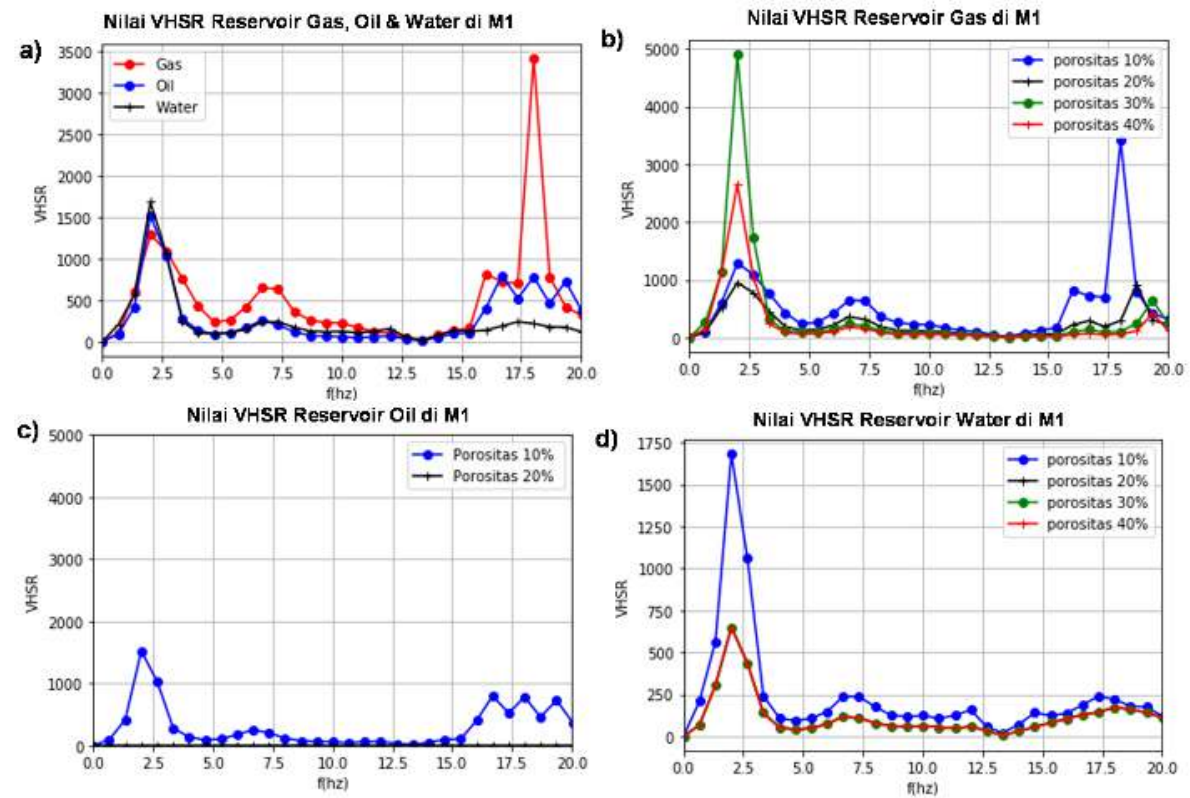

Figure 8. VHSR curves on M1 receiver. a) VHSR curves of gas, oil and water reservoir, b) VHSR curves of gas reservoir with porosity variations, c) VHSR curves of oil reservoir with porosity variations and d) VHSR curves of water reservoir with porosity variations
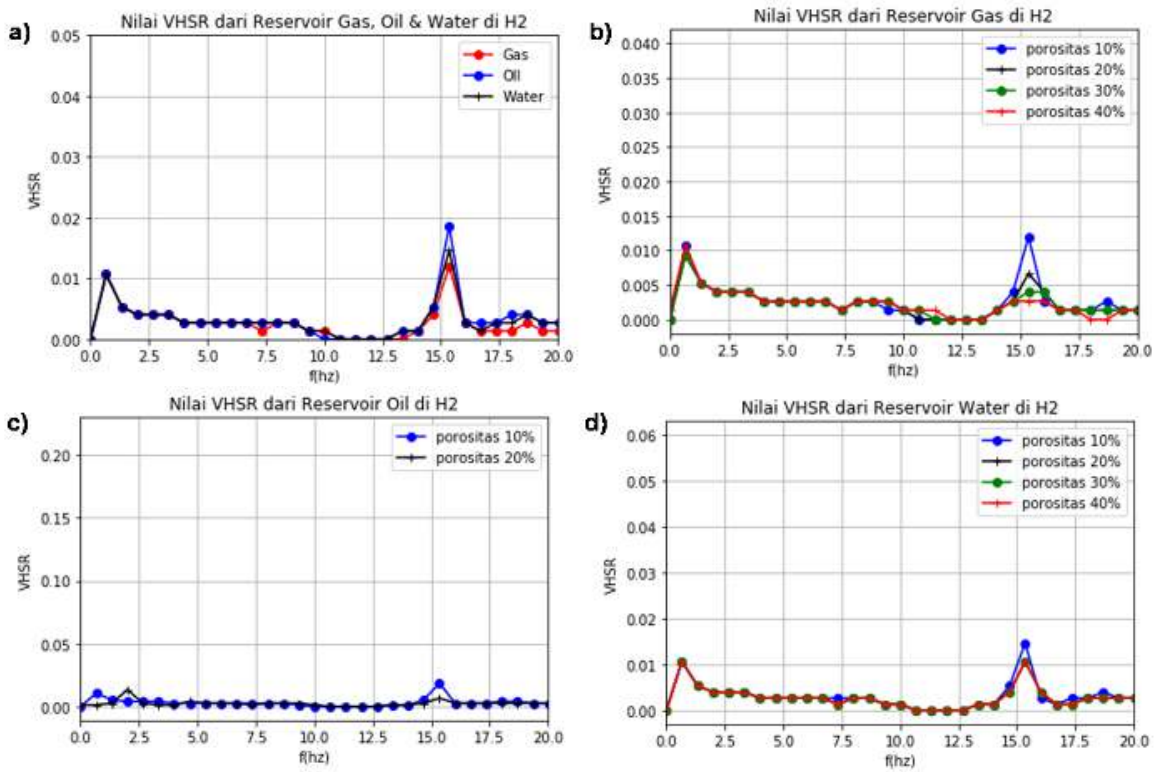

Figure 9. VHSR curves on $\mathrm{H} 2$ receiver. a) VHSR curves of gas, oil and water reservoir, b) VHSR curves of gas reservoir with porosity variations, c) VHSR curves of oil reservoir porosity variations and d) VHSR curves of water reservoir with porosity variations

\section{CONCLUSIONS}

We have applied the numerical modeling of 2D seismic wave propagation using spectral finite element method to estimate the response of seismic waves passing through the poroelastic medium from a hydrocarbon reservoir. A hybrid simple model of the elastic - poroelastic elastic with a mesoscopic scale element size around $50 \mathrm{~cm}$ was created. Seismograms which 
are recorded in the poroelastic and second elastic medium show the existence of slow $\mathrm{P}$ compressional waves following fast $\mathrm{P}$ compressional waves that do not appear on the seismogram of the first elastic medium. The curves of Vertical to horizontal spectrum ratio (VHSR) which are observed from seismograms recorded in the poroelastic and the second elastic medium show that the peak of VHSR values at low frequency correlated with the fluid of poroelastic reservoir. The highest VHSR value at the low frequency which is recorded on the seismogram is above the $2.5 \mathrm{~Hz}$ frequency for reservoirs containing gas and oil in the second elastic medium, while for the medium containing water is the highest VHSR value is below the $2.5 \mathrm{~Hz}$ frequency.

\section{ACKNOWLEDGMENTS}

We would like to say our gratitude to Geophysics Laboratory of Faculty of Mathematics and Natural Sciences of Gadjah Mada University for financial support and PT. Chevron Indonesia for hardware donations in this research.

\section{REFERENCES}

1 Biot, M. A. 1956. Theory of elastic waves in a fluid-saturated porous solid I Low frequency range. Journal of the acoustical Society of america, Vol. 28, pp. 168-178.

2 Biot, M. A. 1956. Theory of propagation of elastic waves in a fluid-saturated porous solid II Higher frequency range. Journal of the acoustical Society of america, Vol. 28, pp. 179191.

3 Zhu, X., \& McMechan, G. A. 1991. Numerical simulation of seismic responses of poroelastic reservoirs using Biot theory. Geophysics, Vol. 56, No. 3, pp. 328-339.

4 Dai, N., Vafidis, A., \& Kanasewich, E. R. 1995. Wave propagation in heterogeneous, porous media: A velocity-stress, finite-difference method. Geophysics, Vol. 60, No. 2, pp. 327-340.

5 Martin, R., Komatitsch, D., \& Ezziani, A. 2008. An unsplit convolutional perfectly matched layer improved at grazing incidence for seismic wave propagation in poroelastic media. Geophysics, Vol. 73, No. 4, pp. T51-T61.

6 Sudarmaji, Sismanto, Waluyo \& Soedijono, B. 2016. AIP Conf. Proc.1755100001, pp. 17.

7 Komatitsch, D., \& Tromp, J. 1999. Introduction to the spectral element method for threedimensional seismic wave propagation. Geophysical journal international, Vol. 139, No. 3, pp. 806-822.

8 Morency, C., \& Tromp, J. 2008. Spectral-element simulations of wave propagation in porous media. Geophysical Journal International, Vol. 175, No. 1, pp. 301-345.

9 Komatitsch, D., Erlebacher, G., Göddeke, D., \& Michéa, D. 2010. High-order finiteelement seismic wave propagation modeling with MPI on a large GPU cluster. Journal of computational physics, Vol. 229, No. 20, pp. 7692-7714.

10 Sudarmaji, Rudianto, I., Rahmareza, M.K., \& Alfontius, Y. 2019. Seismic Wave Propagation Simulation in a Poro-elastic Medium Using Spectral Method Elements in MPI-GPU Cluster: Study Case of Anticline Reservoir Trap. Indonesian Journal of Applied Physics, Vol. 9, No. 1, pp. 1-9.

11 Saenger, E. H., Schmalholz, S. M., Lambert, M. A., Nguyen, T. T., Torres, A., Metzger, S., Habiger, R.M., Müller, T., Rentsch, S., \& Méndez-Hernández, E. 2009. A passive seismic survey over a gas field: Analysis of low-frequency anomalies. Geophysics, Vol. 74, No. 2, pp. o29-o40. 
12 Ali, M.Y., Berteussen, K.A., Small, J. \& Barkat, B. 2009. Geophysical Prospecting, pp. 125.

13 Pandito, R. H.B. 2018. Passive Seismic for Hydrocarbon Indicator: Between Expectation and Reality. IOP Conf. Series: Earth and Environmental Science, Vol. 132, No. 1, p. 012035.

14 Ebrahimi, M., Moradi, A., \& Seidin, H. 2017. Analysis of Low-Frequency Passive Seismic Attributes in Maroun Oil Field, Iran. Journal of the Earth and Space Physics, Vol. 43, No. 4, pp. 11-26.

15 Haris, A., Riyanto, A.Syahputra, R.,Gunawan, A., Panguriseng, M.P., Nuratmaja, S., \& Adriansyah. 2019. Journal of Geophysics and Engineering, pp. 1-14.

16 Wenzlau, F., \& Müller, T. M. 2009. Finite-difference modeling of wave propagation and diffusion in poroelastic media. Geophysics, Vol. 74, No. 4, pp. T55-T66. 